\title{
O PAPEL DA ARQUEOLOGIA NOS CONFLITOS DECORRENTES DE OCUPAÇÕES IRREGULARES NO SAMBAQUI DA PANAQUATIRA - SÃO JOSÉ DE RIBAMAR - MA
}

The role of Archaeology in dispute arising out of occupations of irregular in Panaquatira Shellmound - São José de Ribamar - MA

Arkley Marques Bandeira ${ }^{1}$

\section{RESUMO}

Este artigo discorre sobre a gestão dos conflitos decorrentes da invasão do Loteamento Costa Atlântica, onde se situa o Sambaqui do Panaquatira, município de São José de Ribamar, Ilha de São Luís - MA. Em 2008, a Superintendência do IPHAN no Maranhão foi informada sobre a existência de habitações irregulares sobre o Sambaqui da Panaquatira. No processo de investigação, múltiplos atores participaram da negociação em torno da proteção e preservação deste sítio arqueológico, a exemplo dos proprietários do Loteamento, Prefeitura de São José de Ribamar, Advocacia Geral da União, Ministério Púbico Federal, Justiça Federal, Polícia Federal, além do IPHAN - MA. Os desdobramentos resultaram na preservação do sítio arqueológico e o comprometimento da não reocupação da área do Sambaqui, bem como outros avanços.

Palavras-chave: Sambaqui da Panaquatira - Conflito - Posseiros

\section{ABSTRACT}

This article discusses the management of conflicts arising from the invasion of Allotment Atlantic Coast, where lies the Sambaqui da Panaquatira, São José de Ribamar, Island of São Luís - MA. In 2008 the Superintendent of IPHAN Maranhão was informed about the existence of irregular housing on the Sambaqui da Panaquatira. In the research process multiple actors participated in the negotiations around the protection and preservation of this archaeological site, like the owners of Allotment, at São Jos de Ribamar, Attorney General's Office, Federal Ministry Pubic, Federal Court, Federal Police, beyond IPHAN - MA. The developments resulted in the preservation of archaeological and commitment not reoccupation Sambaqui area, as well as other advances.

Keywords: Panaquatira Shellmound- Conflict - Squatters

\section{RESUMEN}

En este artículo se analiza la gestión de los conflictos derivados de la invasión de la área del Costa Atlántica, donde se encuentra el Concheiro Panaquatira, en São José de Ribamar, Isla São Luís - MA. En 2008 se informó a la Superintendencia de IPHAN Maranhão sobre la existencia de viviendas irregulares en lo Concheiro Panaquatira. En el proceso de investigación múltiples actores participaron en las negociaciones en torno a la protección y conservación de la zona arqueológica, al igual que los propietarios, Subdivisión de la Ciudad de San José de Ribamar, Procuraduría General de la Nación, Ministerio Público Federal,

\footnotetext{
${ }^{1}$ Doutor em Arqueologia pelo Museu de Arqueologia e Etnologia da Universidade de São Paulo. Coordenador da Casa da Memória do Ecomuseu do Sítio do Físico, São Luís - MA. Email: arkleybandeira@hotmail.com
} 
Tribunal Federal, la Policía Federal, así como IPHAN - MA. Los acontecimientos dieron lugar a la preservación del patrimonio arqueológico y el compromiso de no volver a ocupar la zona del Concheiro, así como otros avances.

Palabras clave: Concheiro del Panaquatira - Conflicto - Ocupantes

\section{Introdução}

A inserção de uma arqueologia concebida como uma forma de ação social e política no presente (TILLEY, 1998) e o reconhecimento de que esta não está livre de seus laços sociais e políticos e que os arqueólogos sempre trabalharam pressionados por questões colocadas pela própria conjuntura e sociedade (UCKO, 1995) desmistificou o conceito de objetividade ou neutralidade científica para a disciplina.

Este artigo partilha dos pressupostos da Arqueologia Pública quando aborda o papel da gestão de conflitos em torno da preservação do patrimônio arqueológico, tendo em vista a crescente expansão urbana da Ilha de São Luís - MA em direção à linha costeira o que ocasionou a ocupação irregular do Sambaqui da Panaquatira.

O sambaqui da Panaquatira foi identificado em 2006 e registrado no Cadastro Nacional de Sítios Arqueológicos - CNSA - IPHAN (cadastro MA 00113) por Arkley M. Bandeira em 2009. O sítio foi intensamente investigado entre os anos de 2010 e 2012, cujos resultados foram apresentados na Tese de Doutorado deste arqueólogo (BANDEIRA, 2013).

No início da pesquisa, foi percebido o aumento gradativo de ocupações no entorno do sítio arqueológico. Tais ocupações situavam-se na área do Loteamento Costa Atlântica, cujas habitações eram rapidamente construídas com materiais perecíveis, a exemplo de madeira, palha e papelão.

Este fato foi comunicado de imediato a Superintendência do IPHAN do Maranhão, que realizou a primeira vistoria na área em 2008. Constatado o dano eminente ao sítio arqueológico, foi proposto um grupo de trabalho para acompanhar a situação e propor alternativas para proteção e preservação do Sambaqui da Panaquatira.

No decurso de cinco anos de atividades relacionadas a este fato, o patrimônio arqueológico foi apropriado por diferentes atores na condução do processo de implantação do Loteamento Costa Atlântica e os desdobramentos advindos das ocupações irregulares. Esta situação colocou frente a frente os legítimos proprietários, os posseiros e as autoridades. 
Este artigo narra o desencadeamento dos fatos relacionados com a ocupação irregular do Sambaqui da Panaquatira e os desdobramentos dos conflitos resultantes, tendo como cerne a integridade do sítio para o usufruto das atuais e futuras gerações.

\section{A arqueologia do Sambaqui da Panaquatira}

O Sambaqui da Panaquatira está localizado no povoado de mesmo nome, na praia da Ponta Verde, no município de São José de Ribamar, baía de São José, na desembocadura do rio Itapecuru, em área estuarina, caracterizada por um rico ecossistema de mangue. Este município, juntamente com São Luís, Raposa e Paço do Lumiar compõe a Ilha de São Luís.

O Sambaqui da Panaquatira apresentou em sua zona central a UTM 23M 0606517/9720231 (Longitude O 44²' 31" e Latitude S 2 31' 51”), com elevação de 34m acima do nível do mar. A extensão efetiva da área com ocorrência de material arqueológico, totalizando 349,80 hectares.
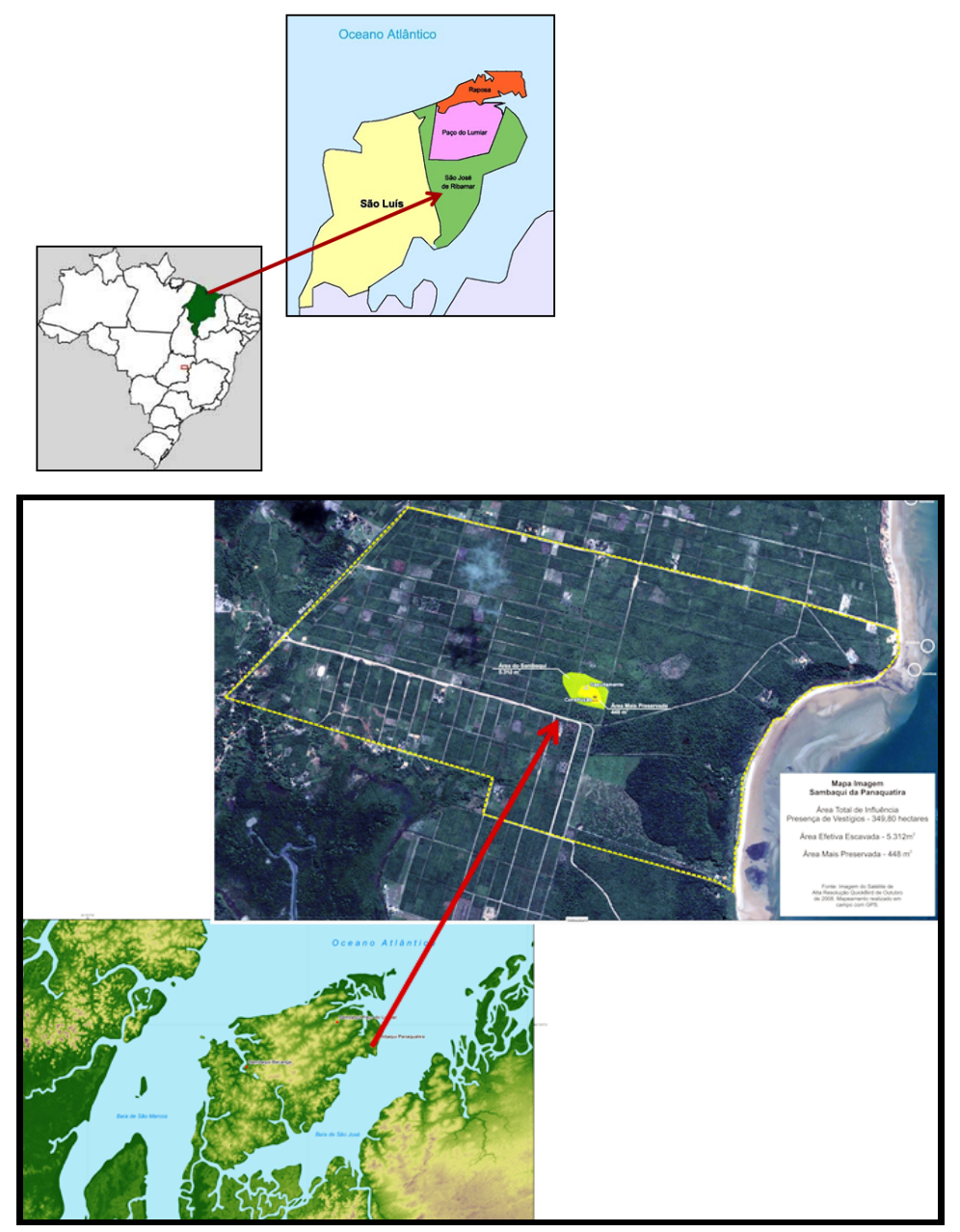

Fig.1 e 2: Inserção geográfica do Sambaqui da Panaquatira, com a demarcação da área de interesse. 


\section{Histórico processual do Sambaqui da Panaquatira}

Em 22 de setembro de 2008 foi aberto o Processo IPHAN n. ${ }^{\circ}$ 01494.000464/200830, para vistoriar o Sambaqui da Panaquatira, tendo em vista as denúncias feitas sobre a existência de habitações irregulares na área do sítio arqueológico, retirada irregular de terra preta e utilização das conchas para pavimentação de estradas.

A presença de pessoas na área do sítio e seu entorno estava causando impactos graves ao patrimônio arqueológico, por uma gama de atividades antrópicas: construção de moradias e colocação de cercas nos terrenos, que causaram impactos aos horizontes arqueológicos subsuperficiais; extração de terra preta e conchas para jardinagem que expuseram significativa quantidade de material arqueológico; desmatamentos e queimadas para plantação de roças que contaminaram o material arqueológico; criação de gado que pisotearam os vestígios em superfície, bem como a implantação de redes elétricas e estradas que atraíram posseiros para a região.

A permanência desta situação poderia comprometer a investigação arqueológica que estava sendo realizada no sítio arqueológico $^{2}$ e impactar irreversivelmente o Sambaqui, inclusive, colocando em risco a integridade dos pesquisadores, que necessitavam diariamente presenciar os conflitos entre os proprietários e posseiros.

Naquele momento, toda a área do Sambaqui, bem como seu entorno faziam parte do Loteamento Costa Atlântica, administrado pela Oliveira Empreendimentos Imobiliários, da Sra. Benedita Conceição Morais e Sr. Paulo Roberto Oliveira, que representavam os proprietários, Srs. Felíntro Elísio Cutrim e Edmundo Elísio Cutrim.

A vistoria averiguou a procedência das denúncias e constatou os danos causados ao sítio arqueológico em virtude das ocupações irregulares e a extração de terra preta: “os dados arqueológicos perdidos pelo processo de separação da terra-preta do material arqueológico têm prejudicado o avanço de uma pesquisa que tem chamado a atenção da comunidade científica brasileira" (IT nº 260/2008 DT 3ª SR/IPHAN, 2008: 03).

\footnotetext{
${ }^{2}$ A pesquisa realizada neste sítio é vinculada ao projeto Sambaquis do Maranhão, autorizada pela Portaria IPHAN n ${ }^{\circ}$. 16/12, Processo $n^{\circ}$ 01494.000593/2008-28. Este projeto substituiu o antigo projeto acadêmico $O s$ sambaquis do Bacanga, Panaquatira e Paço do Lumiar na Ilha de São Luís - Maranhão: um estudo acerca da paisagem arqueológica, cultura material, padrão de assentamento e subsistência, vinculado ao Programa de Pós-graduação de Arqueologia, Museu de Arqueologia e Etnologia da Universidade de São Paulo. Os resultados das atividades foram incorporados no doutorado deste autor. A portaria de pesquisa foi publicada no D. O. U. n. 245, em 17/12/2008.
} 
A sugestão do técnico nesta mesma peça foi "o despacho de cópia desta informação técnica a prefeitura e a câmara dos vereadores de São José de Ribamar, com o objetivo de ciência do que está acontecendo na área e com uma proposta de busca de uma solução conjunta..." (IT nº 260/2008 DT 3 SR/IPHAN, 2008: 04).

Constatado e confirmado o impacto ao sítio arqueológico pelo IPHAN, o passo seguinte foi conhecer os responsáveis pelas ocupações, tendo em vista a existência de proprietários e posseiros ocupando lotes no sítio, sem moradores vivendo nas habitações já construídas.

Esta situação foi dificultada pelo fato do loteamento não ter sido totalmente vendido, sendo que muitos dos atuais proprietários não tomaram posse dos terrenos e não realizaram o cercamento de suas áreas, favorecendo a ocupação das mesmas por posseiros.

$\mathrm{Na}$ vistoria ficou evidenciada a disputa de terra e o conflito decorrente de interesses entre os proprietários e posseiros no uso e ocupação dos lotes que estão localizados no Sambaqui da Panaquatira:

É preciso salientar que a área, uma vez se encontra em disputa, apresenta grandes riscos à preservação do sítio Panaquatira - Itapari devido às tensões em torno do direito ao usufruto dos seus recursos, assim como a continuidade e aceleração das atividades de exploração de terra preta não está descartada (IT n ${ }^{\circ}$ 07/2009 DT/IPHAN/3 ${ }^{\text {a }}$ SR, 2009: 65).

A tentativa de contatar o Sr. Anderson Herbert Soarez, proprietário da área onde se situa o sítio arqueológico foi frustrada na quarta vistoria realizada pelo IPHAN, no entanto, o técnico da instituição conseguiu conversar com algumas lideranças dos posseiros. Uma delas foi a Sra. Joana que confirmou a formação de uma comunidade no local para ocupar a área (IT nº 08/2009 DT/IPHAN/3 ${ }^{\text {a }}$ SR, 2009: 70).

Em 20 de janeiro de 2009 o Gabinete do IPHAN - MA encaminhou o processo ao Juiz da $1^{\text {a }}$ Vara da Comarca de São José de Ribamar, o Sr. Marcio Castro Brandão, para que intercedesse "junto ao proprietário da área em conflito para que a retirada dos invasores e suas respectivas construções não seja feita com o uso de tratores, uma vez que os mesmos poderão destruir o sítio arqueológico protegido" (Ofício nº 19/2009. $3^{\text {a }}$ SR/IPHAN, 2009: 83).

Aparecem no processo os representantes legais do Loteamento Costa Atlântica, a Sra. Benedita Conceição Morais e o Sr. Paulo Roberto Oliveira, representantes dos proprietários, Srs. Felíntro Elísio Cutrim e Edmundo Elísio Cutrim: 
O Sr. Oliveira afirmou a execução da decisão do juiz de expulsão dos invasores da área ocupada na próxima semana, requerendo a participação do IPHAN na determinação de quais áreas não deverão ser atingidas pelas ações dos tratores que derrubarão as estruturas edificadas, assim como a presença do arqueólogo da instituição para acompanhar tudo (IT nº 64/2009 DT/IPHAN/3ª SR, 2009: 85).

Em 27 de fevereiro de 2009 foi realizada reunião de nivelamento com acordo amigável entre os proprietários do Loteamento Costa Atlântica, IPHAN e este arqueólogo para a proteção e fiscalização do Sambaqui da Panaquatira, quando da reintegração de posse dos lotes ocupados irregularmente aos seus devidos donos.

$\mathrm{O}$ referido acordo também endossou o entendimento entre os coordenadores do projeto de pesquisa Sambaquis do Maranhão e os representantes do Loteamento Costa Atlântica para cessão permanente dos lotes 11,12, 13 e 14 da quadra 92 para a pesquisa arqueológica. Em paralelo foi acordada a realização de oficinas de educação patrimonial e construção de um museu de sítio para expor os vestígios coletados e envolver o público na preservação do sítio arqueológico com visitas in loco (IT n n 79/2009 DT/IPHAN/3 ${ }^{\text {a }}$ SR, 2009: $88)$.

O entendimento entre as partes legítimas no processo foi firmado em Ofício n. 36, protocolado no IPHAN em 27 de fevereiro de 2009, no qual o procurador legal dos proprietários, Sr. Carlos Amorim, reserva os referidos lotes para pesquisa arqueológica, em área de $1.800 \mathrm{~m}^{2}$, confirmando que não haverá danos aos mesmos na reintegração de posse, já que a área será preservada mesmo com implantação do loteamento.

Neste intervalo o Juiz da $1^{\text {a }}$ Vara da Comarca de São José de Ribamar, Sr. Juiz Marcio Castro Brandão, fez valer a execução da reintegração de posse em favor dos Srs. Felíntro Elísio Cutrim e Edmundo Elísio Cutrim, em face aos esbulhos cometidos por um grupo de posseiros no Loteamento Costa Atlântica, inclusive na área do Sambaqui do Bacanga (Justiça Estadual, Processo n.1842/08: 2008: 101).

Em 06 de março de 2009 foi realizada a reintegração de posse executada pelo Comandante do $6^{\circ}$ BDPM, Major Alexandre Francisco dos Santos, $1^{\mathrm{o}}$ Tenente Neivando Ferreira Leite e pelo Comandante da Operação, Capitão José Maria Padro.

Foi acordado entre as partes que as estruturas que estavam sobre o Sambaqui da Panaquatira não seriam mexidas na reintegração de posse, tendo em vista o agravamento do impacto. Neste caso, as edificações seriam mantidas para posterior retirada pelos arqueólogos, quando da retomada das escavações no sítio. 
A repercussão da reintegração de posse foi sentida na Imprensa, que noticiou o conflito entre as partes e abordou pela primeira vez a existência do Sambaqui da Panaquatira na área em litígio:

Um documento do Instituto do Patrimônio Histórico e Artístico Nacional (Iphan) informou que parte do local é um sítio arqueológico, e por isso deve ser preservado. Funcionários do órgão estiveram no início da manhã na ocupação, a fim de demarcar a área onde antes era um cemitério indígena, para que não fosse atingida por máquinas e tratores (JORNAL PEQUENO, 2009).

Interessante pontuar, que apesar do processo n. 1842/08 não mencionar a proteção do patrimônio arqueológico, a intensa participação do IPHAN - MA e dos coordenadores do Projeto Sambaquis do Maranhão nas negociações para proteção do Panaquatira surtiram efeito e o foco foi deslocado da posse versus propriedade legal para a permissão ou não da ocupação em área do sítio arqueológico:

O advogado dos ocupantes, Pedro Jarbas, afirmou que recorreu da decisão expedida pelo juiz Márcio Castro Brandão e entrou com um pedido na Justiça Federal, no intuito de tentar provar que não apenas uma parte, mas quase toda a área faz parte do sítio arqueológico, e que, portanto, se não pode ser habitada, também não poderá ser comercializada. "Neste momento a decisão mais correta e sensata a fazer é desocupar a área, afinal, isso foi determinado judicialmente. No entanto, no futuro a história pode ser outra, pois hoje eles desocupam a área, mas em outro momento podem retornar, caso a decisão seja favorável a eles", relatou (JORNAL PEQUENO, 2009).
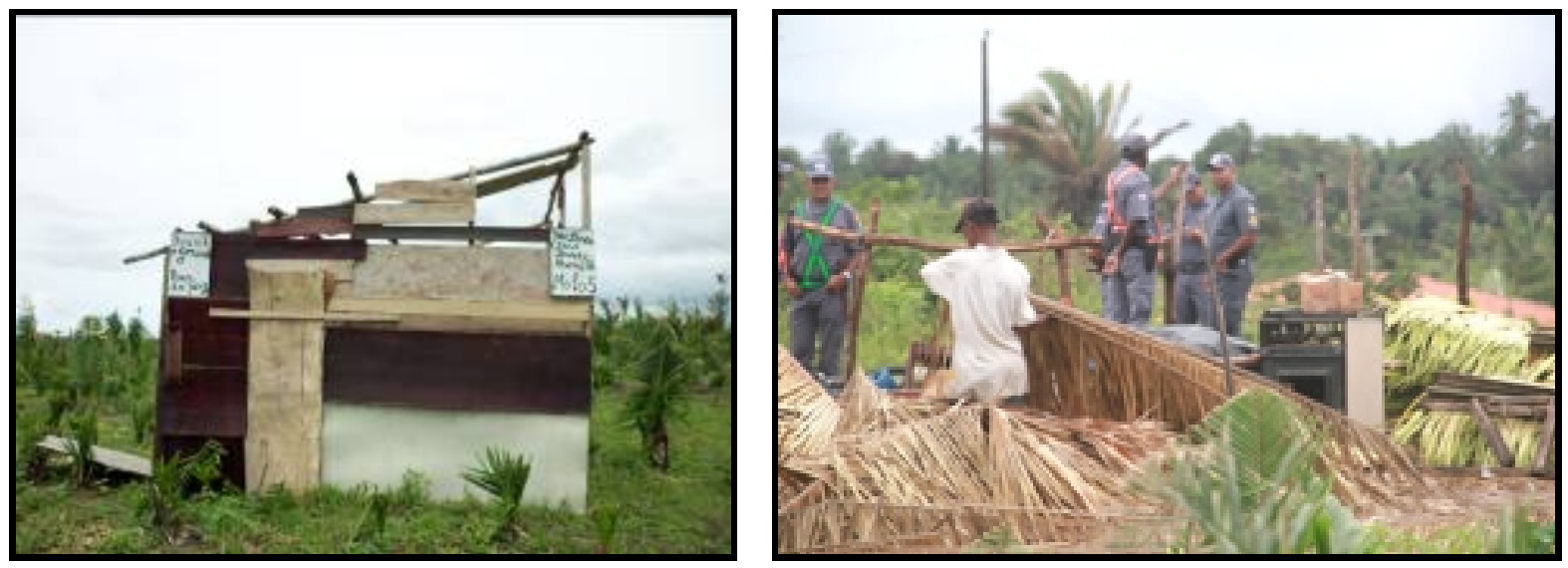

Fig.3 e 4: Edificações sendo demolidas na reintegração de posse na área do Sambaqui. Fotos: Jornal Pequeno, 2009.

Passados seis meses da reintegração de posse, novas ocupações irregulares foram observadas na área do Loteamento Costa Atlântica, inclusive, com maior intensidade e organização. Se as primeiras ocupações eram espontâneas e feitas com materiais perecíveis, 
neste segundo momento as edificações eram de alvenaria e estavam espalhadas por uma área bem maior.

Com vistas a interromper as novas ocupações, uma segunda reintegração de posse foi autorizada pela Justiça Estadual, conforme Ofício n. 583/2009, do $6^{\circ}$ Batalhão Metropolitano do Governo do Maranhão, em 14 de outubro de 2009. Para tanto foi agendada uma audiência prévia entre as partes, inclusive o IPHAN - MA e os coordenadores do Projeto Sambaquis do Maranhão, para compatibilizar a ação policial e a preservação do Sambaqui da Panaquatira.

O resultado da reintegração de posse ficou exposto na narrativa do técnico do IPHAN que acompanhou a ação:

A área da invasão não afetou os horizontes arqueológicos do Sambaqui da Panaquatira. A propósito, a estrutura mais próxima do referido sítio arqueológico encontra-se a cerca de 500 metros de perímetro. E nem as atividades de execução da liminar da reintegração de posse provocaram qualquer dano ao patrimônio arqueológico nacional. $\mathrm{Na}$ oportunidade foi fixada a placa de identificação do sítio arqueológico em questão, como forma de orientar os ocupantes e transeuntes da área

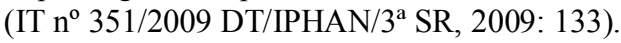

A incompetência da Justiça Estadual em julgar assuntos referentes o patrimônio arqueológico brasileiro, já que se trata de bem difuso e coletivo da esfera da União demandou a entrada do Ministério Público Federal, através da Procuradoria da República, conforme Ofício $n^{\circ}$ 406/2010 - ASS/PR/MA, de 12 de maio de 2010:

Tramita nesta Procuradoria da República o Procedimento Administrativo em epígrafe, instaurado com a finalidade de apurar suposta ameaça ao patrimônio ambiental e arqueológico, decorrente de esbulho praticado por uma quadrilha atuante no município de São José de Ribamar, objeto de Ação de Reintegração de Posse n. 1842/2008, que tramita na justiça daquela comarca. Diante do exposto, com vistas à apuração dos fatos em toda a sua extensão, com base no art. 129, VI, da $\mathrm{CF} / 88$, e do art. $8^{\circ}$, II, da Lei Complementar n. ${ }^{\circ}$ 75/93, requisito a Vossa Senhoria nova vistoria in loco, devendo indicar eventuais responsáveis pela possível degradação do patrimônio arqueológico, bem como adotar as medidas inerentes ao exercício do poder de polícia, no prazo de 20 (vinte) dias (MPF, Procedimento Administrativo $\mathrm{n}^{\mathrm{o}}$ 1.19.000.000245/2010-90: 2010: 150).

A partir deste documento o processo foi transferido para esfera federal, fato que desagradou os proprietários do terreno, tendo em vista todo o retrabalho de mobilização e nova tramitação do julgamento. Além disso, os custos processuais e de reintegração de posse são bem maiores na esfera federal, do que na estadual.

Em atendimento à solicitação do Procurador da República, Sr. Alexandre Soares, o IPHAN promoveu novas vistorias e avaliações complementares para avaliar o estado atual das ocupações em relação à integridade do Sambaqui da Panaquatira: "apesar da expansão da 
notória ocupação da área do condomínio Costa Atlântica, essa não ultrapassou a faixa de 500m de distância do referido sambaqui, não caracterizando dano ao patrimônio nacional"' (IT $n^{\circ}$ 235/2010 CT/ Sup/MA: 2010: 152).

Devido o contexto apresentado o MPF informou ao IPHAN - MA que os autos do Procedimento Administrativo $n^{\circ}$ 1.19.000.000245/2010-90, que tratou dos danos ao Sambaqui da Panaquatira seria enviado à " 4 a Câmara de Coordenação e Revisão do Ministério Público Federal, para fins de arquivamento, sendo facultado a Vossa Senhoria apresentar razões contrárias à medida, caso entenda necessário, no prazo de 10 (dez) dias" (MPF - Ofício n. 937/2010 - ASS/PR/MA: 2010: 155).

Quando o IPHAN estava prestes a encerrar as atividades no Sambaqui do Panaquatira, uma nova denúncia foi feita pela Sra. Alice Silveira Ribeiro, proprietária de lotes no Condomínio Costa Atlântica e representante da recém-fundada Associação dos Proprietários de Lotes do Loteamento Costa Atlântica - APROLCAI, conforme Certidão do MPF, de 06 de julho de 2010.

Neste mesmo período, outro fato agravou o conflito existente na área do Sambaqui do Panaquatira: um cidadão que fazia a vigilância da área para APROLCAI foi torturado e brutalmente assassinado na casa de apoio dos proprietários, em área próxima ao sítio arqueológico.

Diante da situação, o IPHAN - MA novamente se manifestou em favor da proteção e preservação do sítio, ratificando as conclusões observadas na vistoria feita por este arqueólogo, que apontou edificações de alvenaria na área do Sambaqui da Panaquatira, o aumento do número de áreas cercadas, além de ações decorrentes dos moradores na área, a exemplo de queimadas, plantio, extração de terra preta e a presença de animais pastando.
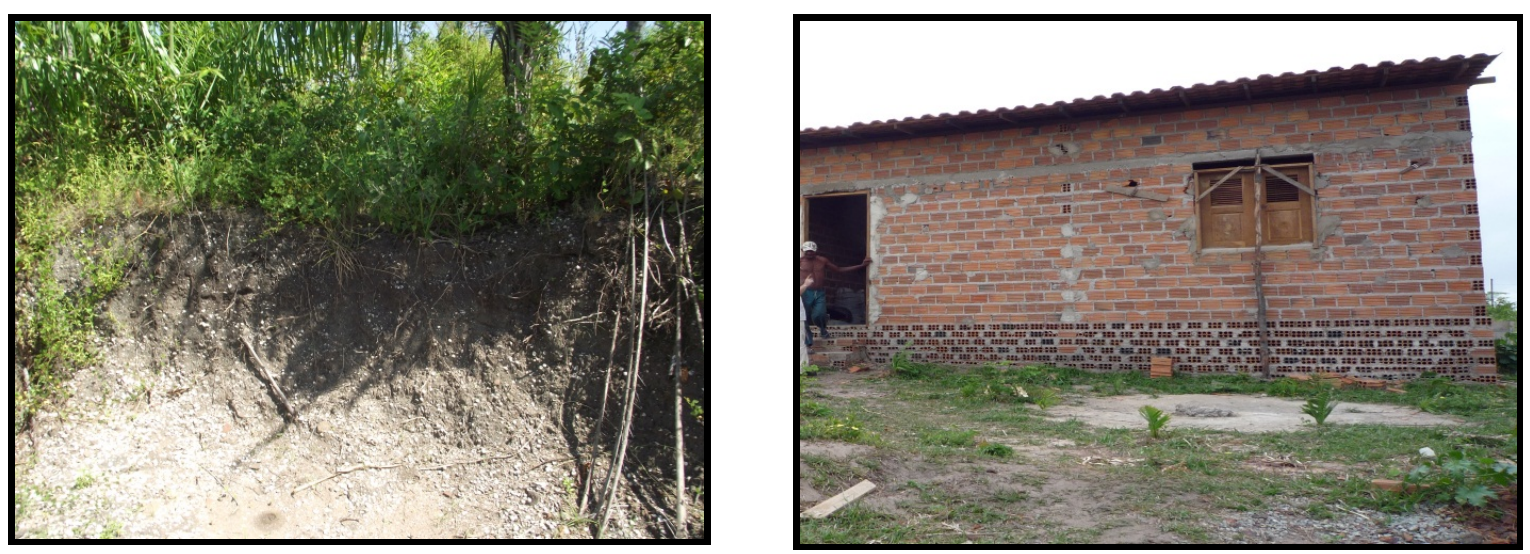

Fig.5 e 6: Casas de alvenaria e permanência da extração de terra preta. Fotos: Arkley Bandeira, 2011. 
Cabe citar que os ocupantes deliberadamente optaram por não ocuparem as áreas com conchas e cerâmicas para não terem problemas com as autoridades. Provavelmente, os posseiros foram aconselhados a se manterem sempre em áreas não caracterizadas como sítio arqueológico, ou seja, sem conchas.

\section{Desdobramentos: avanços e retrocessos}

Confirmada a permanência dos danos ao Sambaqui da Panaquatira partiu-se para proposição de medidas a curto, médio e longo prazo, tendo em vista a proteção, preservação, pesquisa e socialização deste sítio.

Para tanto, o IPHAN - MA convocou os principais responsáveis pela proteção do patrimônio arqueológico, bem como os representantes da APROLCAI e este arqueólogo para uma gestão compartilhada do problema:

\footnotetext{
Venho pelo presente solicitar as presenças de Vossa Senhoria na sede do IPHAN no dia 05 de janeiro de 2011, às 15 horas, para reunião junto com os representantes da empresa Oliveira Empreendimentos Imobiliários Ltda, Advocacia Geral da União, Procuradoria Federal, Polícia Federal e representantes do IPHAN, com o objetivo de discutir a proteção do sítio arqueológico Sambaqui da Panaquatira (Ofício IPHAN $n^{\circ}$. 680/2010 GAB/IPHAN/MA: 2010: 176).
}

Os desdobramentos da reunião apontaram para uma gestão compartilhada em torno da proteção, preservação e socialização do Sambaqui da Panaquatira. Neste espaço foi construída uma agenda, que definiu ações prioritárias para os envolvidos:

- IPHAN - MA: gestão de todo o processo e a comunicação entre os parceiros, bem como o envolvimento da Prefeitura de São José de Ribamar;

- Advocacia Geral da União: acompanhamento dos tramites jurídicos no MPF, representando juridicamente o IPHAN;

- Ministério Público Federal: fiscalização das políticas de proteção ao sítio arqueológico;

- Polícia Federal: apoio nas ações de físcalização e estudos complementares no Sambaqui;

- Prefeitura Municipal de São José de Ribamar: apoio político e administrativo aos parceiros no estudo e divulgação do sítio;

- Projeto Sambaquis do Maranhão: realização de estudos técnicos para delimitação e avaliação arqueológica do sítio; 
- APROLCAI: mobilização dos proprietários em torno da preservação e proteção do Sambaqui da Panaquatira.

Além disso, foi acordado que as medidas mais urgentes seriam a delimitação do Sambaqui da Panaquatira para colocação de uma cerca, sinalização, remoção de todas as habitações irregulares na área do sítio; vigilância constante e ações de socialização do patrimônio arqueológico.

Um episódio importante na gestão do Sambaqui da Panaquatira e do patrimônio arqueológico de São José de Ribamar foi a reunião com o Prefeito do município, Sr. Gil Cutrim, em 14 de janeiro de 2011, que contou com a presença das principiais autoridades envolvidas e resultou em uma visita ao sítio arqueológico.
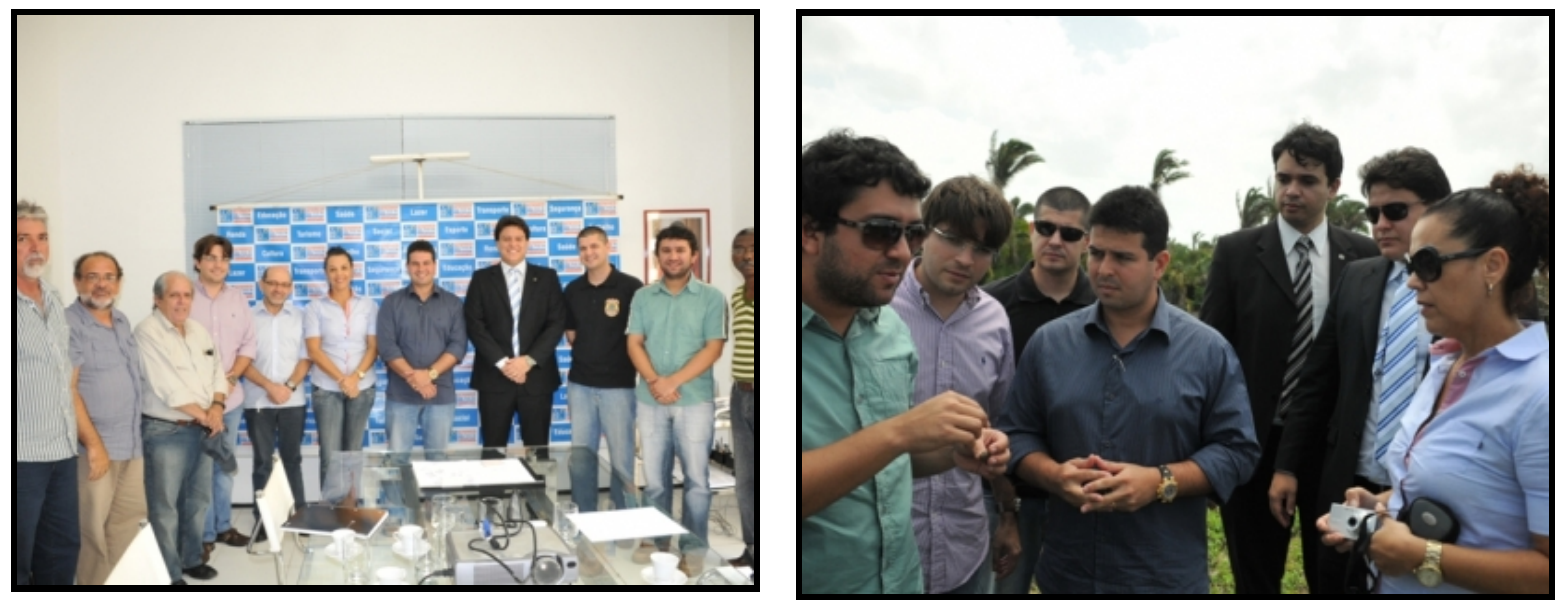

Fig.7 e 8: Autoridades na Prefeitura de São José de Ribamar, em reunião do grupo de trabalho e visitação ao Sambaqui da Panaquatira. Fotos: ASSCOM PMSJR, 2011.

Nesta reunião ficou firmada a delimitação da área do Sambaqui da Panaquatira para colocação de uma cerca e a construção de um museu em São José de Ribamar para socializar o conhecimento produzido na região e para guarda do acervo arqueológico no próprio município:

Kátia Bogéa informou que uma das primeiras medidas a serem adotadas será delimitar toda a área do sítio arqueológico. A superintendente do IPHAN disse acreditar que, em função da riqueza história encontrada no local, o governo federal não medirá esforços para financiar a construção do Museu (ASSCOM PMSJR: 2011: 1).

Em 07 de fevereiro de 2011 foi protocolado no IPHAN o relatório com o Levantamento Topográfico e da delimitação da área para colocação de cerca e o Laudo do estado de conservação do Sambaqui da Panaquatira, São José de Ribamar - MA, de autoria do Geógrafo Bernardo Costa Ferreira e do Arqueólogo Arkley Marques Bandeira, 
respectivamente. Esta ação foi voluntária e contou com o apoio da Prefeitura Municipal de São José de Ribamar.
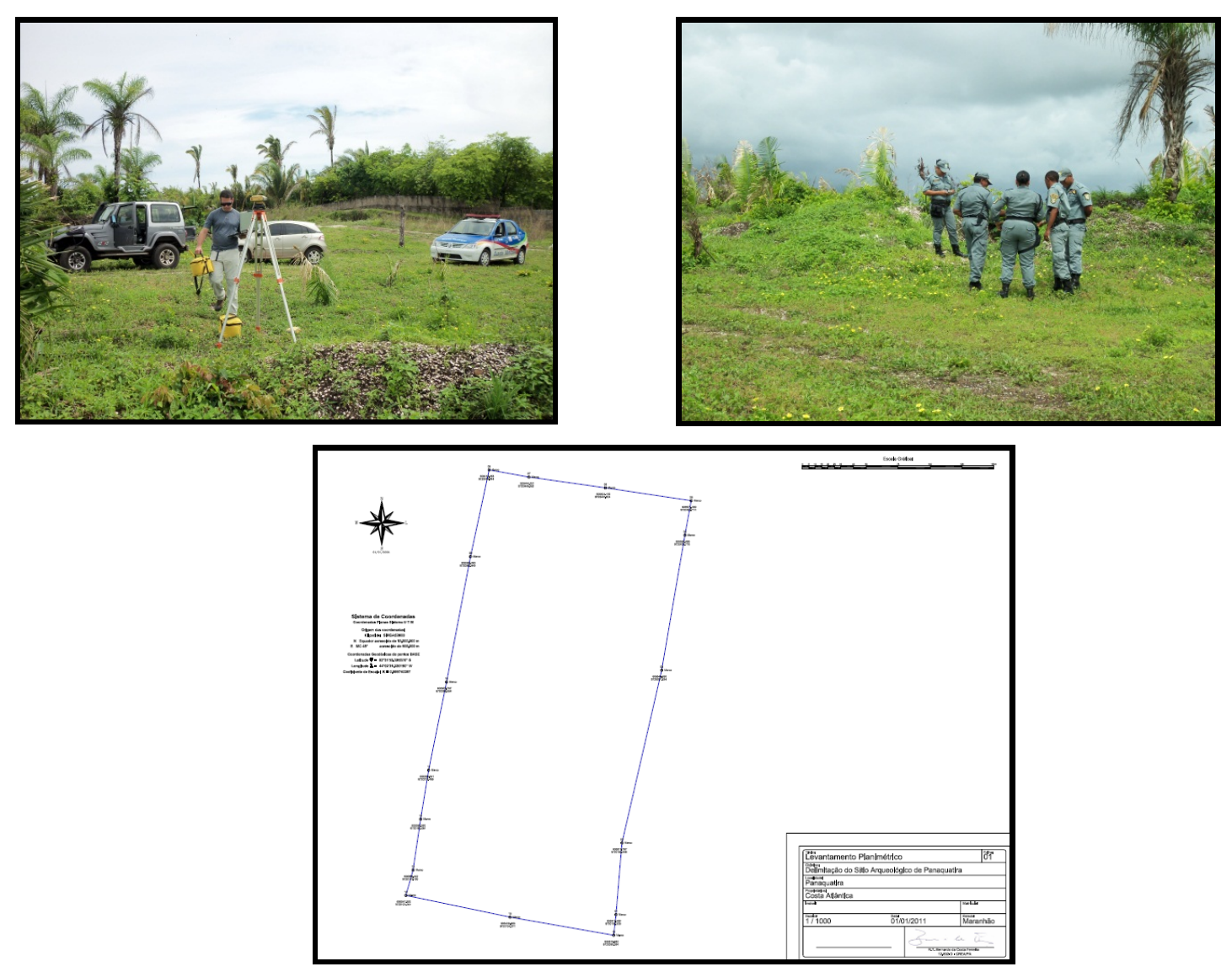

Fig. 9, 10 e 11: Atividade de delimitação do Sambaqui da Panaquatira, com a definição da área a ser cercada. Fotos: Arkley Bandeira, 2011.

Sobre o museu a ser construído foi informado que:

A ideia de construir o Museu da Arqueologia em São José de Ribamar nasceu devido ao fato do município abrigar um importante sítio arqueológico, localizado no polo turístico de Panaquatira. O sítio arqueológico Sambaqui de Panaquatira começou a ser estudado na década de 60 pelo arqueólogo paraense Mário Simões. Mas foi através de estudos recentes realizados pelo arqueólogo Arkley Bandeira que foram descobertos vestígios de um povo que habitou o lugar a, pelo menos, seis mil anos Antes de Cristo. Tudo indica que os habitantes formavam uma comunidade organizada de pescadores. A riqueza história deste local é muito vasta. O Museu, além de todo material que ainda está sendo descoberto no Sambaqui Panaquatira, também abrigará peças de outros sítios arqueológicos da Grande Ilha, por exemplo", explicou Bandeira(ASSCOM PMSJR: 2011: 1).

Em 16 de fevereiro de 2011, a Polícia Federal abriu inquérito policial para apurar possível crime ambiental no Sítio Arqueológico Panaquatira e solicitou ao IPHAN - MA informações acerca dos possíveis responsáveis pelos danos ao patrimônio arqueológico (Ofício n. ${ }^{\circ}$ 35/2011 GAB/DEPOM/DREX/SR/DPF/MA: 2011: 191). 

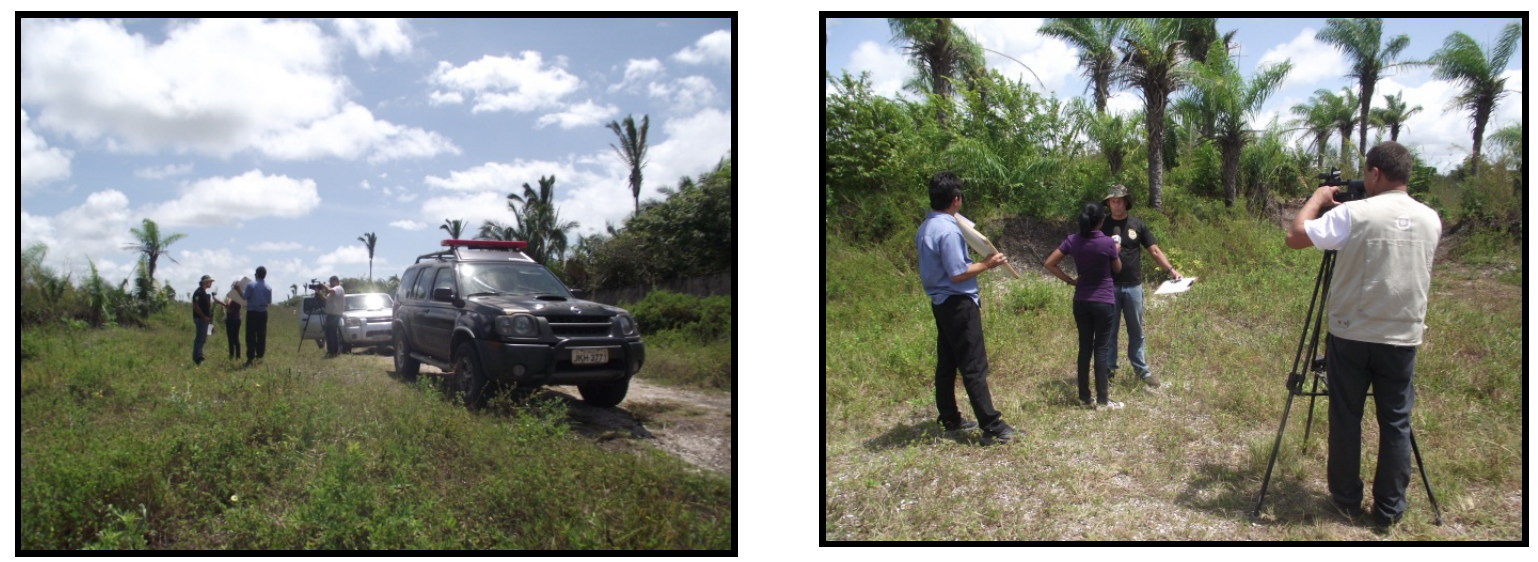

Fig. 12 e 13: Fiscalização da Polícia Federal no Sambaqui da Panaquatira, com cobertura da imprensa. Fotos: Arkley Bandeira, 2011.

Por sua parte, a APROLCAI realizou em 17 de abril de 2011 um mutirão de ações para preparação da terceira reintegração de posse e ocupação imediata dos lotes pelos seus proprietários de direito. Na ocasião foi aberto um espaço para o IPHAN e este arqueólogo realizarem esclarecimentos sobre a importância do Sambaqui da Panaquatira e as responsabilidades dos moradores legais para com a sua proteção e preservação (Ofício APROLCAI n. ${ }^{\circ}$ 5/2011).

Diante dos fatos apresentados o MPF instaurou Inquérito Civil Público a pedido do IPHAN - MA para apurar os novos riscos ocorrentes ao Sambaqui da Panaquatira, tendo em vista a permanência das ocupações irregulares na área deste sítio, inclusive com adensamento populacional e aumento do trânsito de pessoas na área de interesse cultural. Para tanto, solicitou esclarecimentos acerca da suficiência das medidas de proteção adotadas (Ofício n. ${ }^{\circ} 689 / 2011$ - ASS/MP/MA: 2011:239).

Em cumprimento ao acordo firmado entre os envolvidos com a gestão do Sambaqui da Panaquatira, o IPHAN contratou a empresa Ferreira Junior Engenharia Ltda para realização da cerca do Sambaqui. Em 16 de novembro de 2011 iniciaram-se as obras de construção da cerca para o perímetro delimitado pela topografia. 

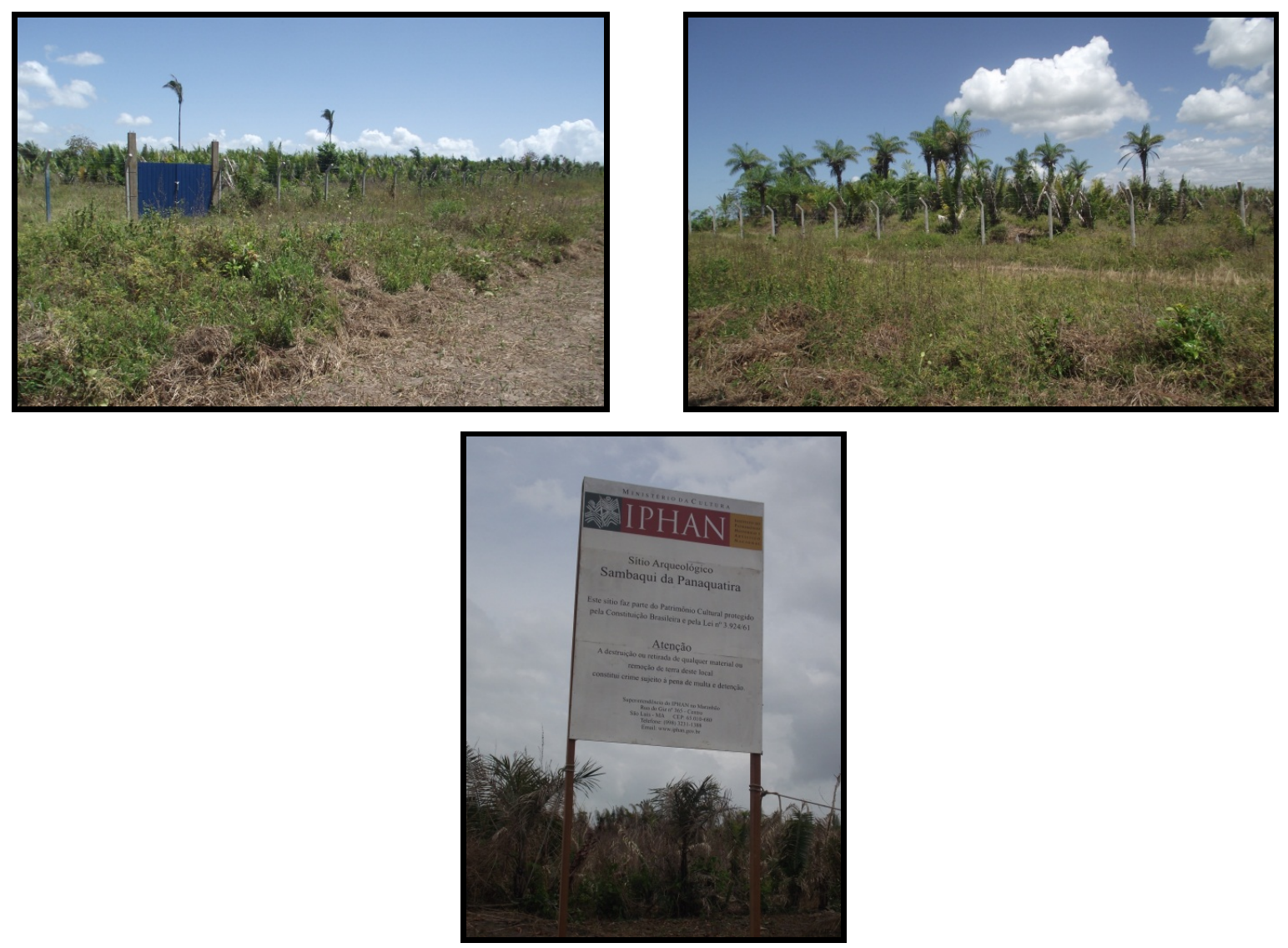

Fig. 14, 15 e 16: Cerca do Sambaqui da Panaquatira e placa de sinalização do sítio. Fotos: Arkley Bandeira, 2012.

Em 09 de janeiro de 2012, a Procuradoria Federal solicitou o ingresso do IPHAN na relação processual, como assistente dos autores, tendo em vista a existência do Sambaqui da Panaquatira. Por se tratar de matéria de interesse federal, já que o patrimônio arqueológico é tratado na esfera da União e sendo competência do IPHAN zelar pela proteção e preservação do patrimônio arqueológico, o interesse da Autarquia estaria justificado. A partir deste momento todo o processo passou a tramitar na esfera federal (PARECER PF/IPHAN/MA n. ${ }^{\circ}$ 3/2012: 2012: 271).

Para tanto, foram realizadas Notificações Extrajudiciais em 05 de janeiro de $2012^{3}$, para os posseiros que possuíam propriedades na área cercada, pois uma nova reintegração de posse foi solicitada pelos proprietários, desta vez tramitando na $8^{\mathrm{a}}$ Vara da Justiça Federal do Maranhão, conforme Processo n. ${ }^{\circ} 18192$ - 85.2011.04.01.3700 (Ofício n. ${ }^{0} 203 / 2012 / 8^{\mathrm{a}}$ VARA/SECVA/JF/MA: 2012: 285).

\footnotetext{
${ }^{3}$ Assinaram as notificações extrajudiciais a Sra. Zilmar Silva e o Sr. Raimundo Lion Meireles, ambos com edificações na área do Sambaqui da Panaquatira. O Sr. Biné, apontado pelos ocupantes como o responsável pelas invasões também foi notificado, apesar de sua propriedade situar-se na área externa ao perímetro cercado. Ele recusou assinar o documento.
} 

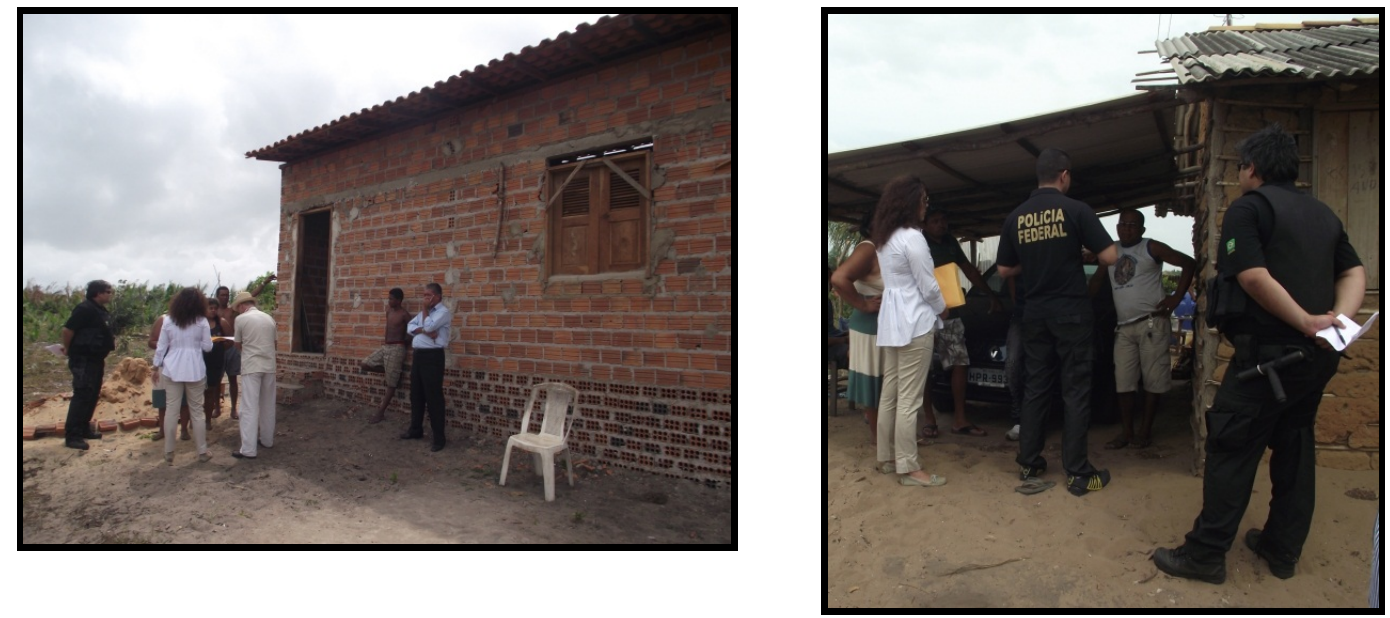

Fig. 17 e 18: Entrega das notificações extrajudiciais para os posseiros em área do Sambaqui. Fotos: Arkley Bandeira, 2012.

Tendo em vista a solicitação do Sr. Juiz da $8^{\text {a }}$ Vara para delimitação da área a ser desocupada é fato que algumas porções do sítio ficaram de fora da cerca, por se tratarem de porções descontínuas do Sambaqui da Panaquatira.

Esta situação foi notificada ao IPHAN e em 17 de abril de 2012 solicitou a este arqueólogo um Parecer Especializado, com base nos estudos que vêm sendo realizados no Sambaqui da Panaquatira, que seja suficiente para proteção deste sítio (Ofício n. ${ }^{\circ}$ 208/2012 GAB/IPHAN/MA: 2012: 291).

Tendo em vista a ampliação da área a ser protegida no sítio arqueológico para além do perímetro cercado, uma nova rodada de estudo foi solicitada à Justiça Federal para tratar dos casos onde o Sambaqui da Panaquatira localiza-se em área dos proprietários legalmente constituídos e onde o sítio está inacessível pela existência de muros e cercas.

O último documento anexado ao processo foi o Memorando da Procuradoria Federal do IPHAN, emitido em 04 de setembro de 2012, que tratou da Ação da Reintegração de Posse, solicitando a manifestação da Autarquia, enquanto os autores do processo se manifestassem em relação aos documentos solicitados pelo Juiz da $8^{\text {a }}$ Vara da Justiça Federal (Memorando n. 113/2012 - Procuradoria Federal/MA/IPHAN: 2012: 306).

Com relação às ações de socialização propostas pelo IPHAN - MA, foi realizado um grande evento para divulgar ao público local e regional a importância da proteção, preservação, conhecimento e divulgação do patrimônio arqueológico, em especial o maranhense. A estratégia foi aliar todos os atores envolvidos com a pesquisa arqueológica na organização do Seminário Nacional Arqueologia e Sociedade: construindo diálogos e parcerias para preservação do patrimônio arqueológico do Maranhão. 
O evento aconteceu entre os dias 17 e 20 de agosto de 2011, no auditório central da Universidade Federal do Maranhão e reuniu mais de 400 participantes de distintas regiões do país e do exterior.
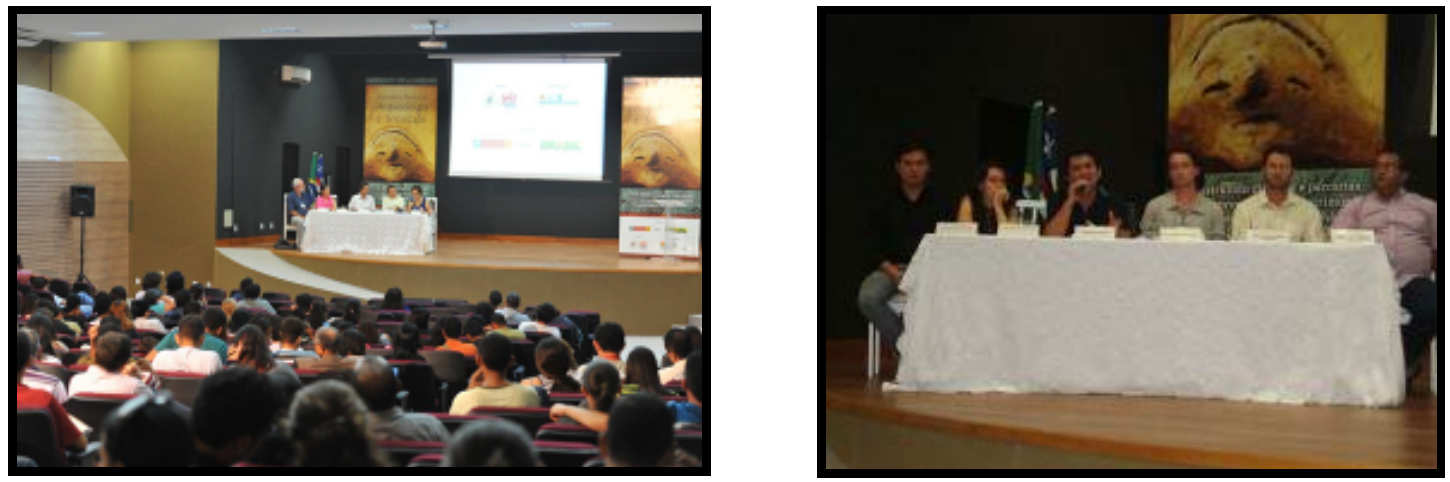

Fig.19 e 20: Mesas Redondas para discutir a produção da arqueologia maranhense sobre a ótica interdisciplinar, com ênfase no projeto acadêmico Sambaquis do Maranhão. Foto: IPHAN, 2011.

Além disso, foi organizada no local do evento a Exposição Maranhão Arqueológico, que contou com mais de 850 visitantes nos três dias de funcionamento.

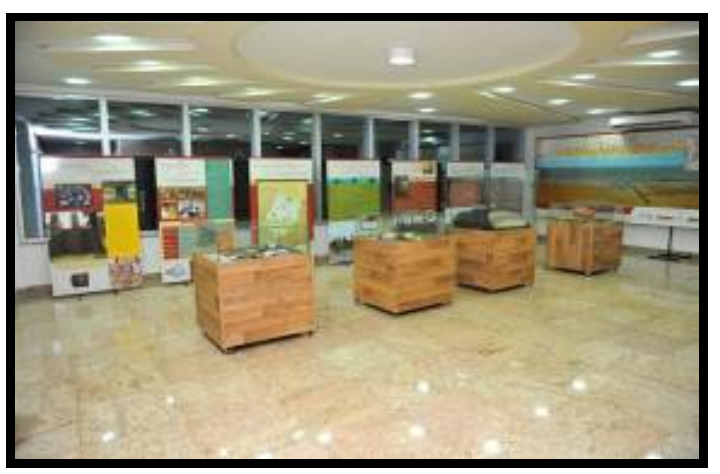

Fig.21: Exposição Maranhão arqueológico antes da abertura oficial. Foto: IPHAN, 2011.

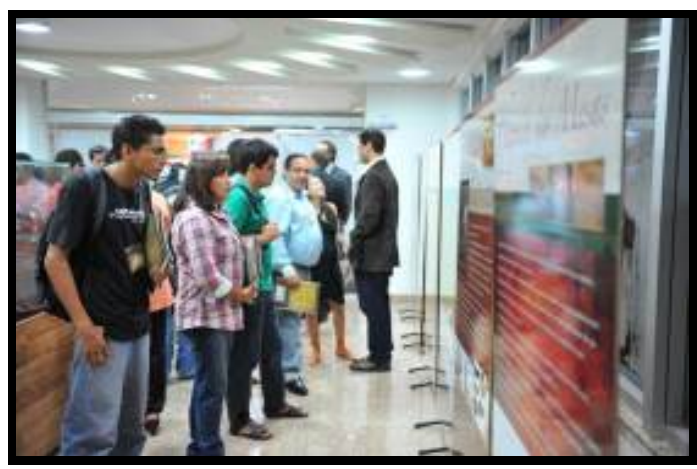

Fig.22: Visitantes apreciam a Exposição Maranhão. Foto: IPHAN, 2011.

Os desdobramentos do Seminário refletiram-se na divulgação do patrimônio pelo Departamento de Jornalismo da TV Mirante, afiliada da Rede Globo, que produziu a série de reportagem Arqueologia: marcas do passado, veiculada entre 16 e 20 de agosto de 2011, nas duas edições diárias do JM TV, enfocando o patrimônio arqueológico maranhense.

\section{Considerações finais}

Este artigo sintetizou com brevidade o histórico processual surgido de denúncias de destruição e delapidação do Sambaqui da Panaquatira por ocupações irregulares e extração de terra preta e concha. 
O desenrolar do processo envolveu múltiplos atores, com interesses e anseios diferenciados, mas que se uniram em torno da preservação deste sítio arqueológico. Ao longo de mais de cinco anos de processo todos os entes da administração pública brasileira, foram envolvidos direta ou indiretamente na gestão dos conflitos decorrentes, primeiramente entre os proprietários e posseiros; e da competência jurídica para julgar o processo: esfera estadual ou federal.

Além disso, alguns órgãos que inicialmente acompanharam timidamente o desenrolar dos fatos, em algum momento se fizeram presentes na luta pela proteção e preservação do Sambaqui da Panaquatira.

Não é exagero afirmar que apesar de parcela significativa do Sambaqui ter sido afetada por atividades antrópicas, muitos avanços foram alcançados, tendo em vista a ação coordenada para uma gestão compartilhada para a proteção, preservação, pesquisa e socialização do bem cultural.

O primeiro avanço foi o envolvimento de distintas esferas do poder no processo do Sambaqui da Panaquatira, situação que reacendeu o pacto pela gestão compartilhada dos conflitos na sociedade presente e chamou a atenção para a situação do patrimônio arqueológico maranhense.

Outro avanço se deu com a mobilização tanto dos proprietários, como dos posseiros, em torno da preservação e proteção do Sambaqui da Panaquatira. Esta ação relativamente simples evitou que novas edificações fossem construídas na área do sítio delimitada para proteção e preservação.

Em relação à produção e socialização do conhecimento, as pesquisas arqueológicas no Sambaqui do Panaquatira resultaram em duas teses de doutorado já defendidas e uma terceira em etapa de conclusão ${ }^{4}$.

No aspecto de divulgação, o Seminário Nacional Arqueologia e Sociedade: construindo diálogos e parcerias para preservação do patrimônio arqueológico do Maranhão e toda a programação do evento colocou a Arqueologia Maranhense no mapa da pesquisa científica do Brasil, apontando as potencialidades e desafios na proteção, preservação, pesquisa e socialização do patrimônio cultural regional.

\footnotetext{
${ }^{4}$ Ocupações humanas pré-coloniais na Ilha de São Luís - MA: inserção dos sítios arqueológicos na paisagem, cronologia e cultura material cerâmica, de autoria de Arkley Marques Bandeira; e Bacanga, Panaquatira e Paço do Lumiar: estudo das indústrias líticas presentes em sambaquis na Ilha de São Luís, Maranhão, por cadeias operatórias e sistema tecnológico, de autoria de Abrahão Sanderson Nunes F. da Silva, defendidas no PPG - MAE - USP. A tese em finalização é de autoria de Renato Akio Ikeoka, com o título Análise de cerâmicas arqueológicas do Sambaqui do Bacanga e Panaquatira (MA) por EDXRF Portátil, a ser defendida no Laboratório de Física da Universidade Estadual de Londrina.
} 
Para não falar apenas dos aspectos positivos, muitas ações se perderam pelo caminho e necessitam de mais atenção para o seu fortalecimento, é o caso do Museu de Arqueologia de São José de Ribamar. A permanência da mesma estrutura governativa permitirá que nova rodada de negociação foque o tema da socialização do patrimônio arqueológico no próprio município e a responsabilidade da municipalidade em conduzir este processo.

Outro ponto a ser enfrentado é a vigilância da área cercada pela polícia. Apesar das constantes vistorias feitas pelo IPHAN e os participantes do Projeto Sambaquis do Maranhão terem constatado que a área cercada permanece íntegra e sem ocupação, que a sinalização e a cerca não foram depredadas, faz-se necessária ações periódicas de monitoramento da área.

O caso apresentado é um exemplo típico do papel político e social da arqueologia no enfrentamento das agendas mais atuais da contemporaneidade. O papel da disciplina na condução do processo e como aliada dos agentes de preservação e proteção do bem arqueológico se desdobrou em ações até então inexistentes para o Estado do Maranhão.

O comprometimento da arqueologia resultou no fortalecimento dos laços institucionais em torno do patrimônio cultural, através da ação participativa de distintas vozes. Os fatos narrados neste artigo não estão encerrados. No fluxo e refluxo das ações institucionais e civis, muitos avanços estão por vir e a arqueologia tem o seu papel de fomentadora desses processos, pois como bem lembra Tilley, uma arqueologia apolítica é um mito acadêmico perigoso. Toda arqueologia é política (TILLEY, 1998).

\section{Referências bibliográficas}

ASSOCIAÇÃO DOS PROPRIETÁRIOS DO LOTEAMENTO CONSTA ATLÂNTICA APROLCAI. Ofício APROLCAI n. ${ }^{\circ}$ 5/2011.

BANDEIRA, Arkley Marques. Laudo do estado de conservação do Sambaqui da Panaquatira, São José de Ribamar - MA. São Luís, 2011.

Ocupações humanas pré-coloniais na Ilha de São Luís - MA: inserção dos sítios arqueológicos na paisagem, cronologia e cultura material cerâmica. Tese de Doutorado. 2013. Tese. Programa de Pós-graduação em Arqueologia. Museu de Arqueologia e Etnologia, Universidade de São Paulo. São Paulo, 2013.

FERREIRA. Bernardo Costa. Levantamento Topográfico e de delimitação da área do Sambaqui da Panaquatira para colocação de cerca. São Luís, 2011.

IPHAN. IT n ${ }^{\circ}$ 260/2008 DT $3^{\text {a }}$ SR/IPHAN, 2008: 03.

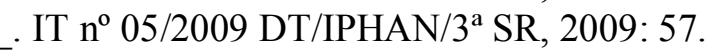

. IT no 07/2009 DT/IPHAN/3 ${ }^{\text {a }}$ SR, 2009: 65. 
. IT n ${ }^{\mathrm{o}}$ 08/2009 DT/IPHAN/3 ${ }^{\mathrm{a}}$ SR, 2009: 70.

. Ofício no ${ }^{0} .19 / 2009.3^{\text {a }}$ SR/IPHAN, 2009: 83.

. IT $n^{\circ}$ 64/2009 DT/IPHAN/3 ${ }^{\mathrm{a}}$ SR, 2009: 85.

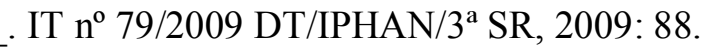

. IT n ${ }^{\circ}$ 96/2009 DT/IPHAN/3 ${ }^{\text {a }}$ SR, 2009: 118.

. IT no 351/2009 DT/IPHAN/3ª SR, 2009: 133.

. IT n ${ }^{\mathrm{o}}$ 235/2010 CT/ Sup/MA: 2010: 152.

. Ofício IPHAN nº. 680/2010 GAB/IPHAN/MA: 2010: 176.

. Ofícios 177 e 178/2011/GAB/IPHAN/MA: 2011: 220.

. Ofício n. ${ }^{\circ}$ 208/2012 GAB/IPHAN/MA: 2012: 291.

. PARECER PF/IPHAN/MA n. ${ }^{\circ}$ 3/2012: 2012: 271.

. Memorando n. 113/2012 - Procuradoria Federal/MA/IPHAN: 2012: 306.

JORNAL PEQUENO, São Luís, Edição. Online, 2009.

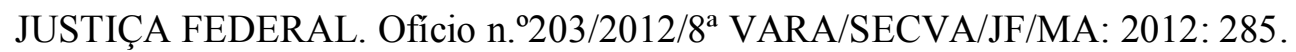

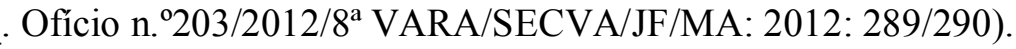

MARANHÃO. Justiça Estadual do Maranhão, Processo n.1842/08: 2008: 101.

MINISTÉRIO PÚBLICO FEDERAL. Ofício n 406/2010 - ASS/PR/MA, 2010.

. Ofício n. 937/2010 - ASS/PR/MA: 2010: 155.

. Ofício n. ${ }^{\circ} 689 / 2011-$ ASS/MP/MA: 2011: 239.

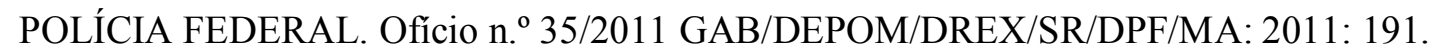

PREFEITURA MUNICIPAL DE SÃO JOSÉ DE RIBAMAR. ASSCOM PMSJR: 2011: 1.

SANDERSON, Abrahão Nunes F. da Silva. Bacanga, Panaquatira e Paço do Lumiar: estudo das indústrias líticas presentes em sambaquis na Ilha de São Luís, Maranhão, por cadeias operatórias e sistema tecnológico. Tese. Programa de Pós-graduação em Arqueologia. Museu de Arqueologia e Etnologia, Universidade de São Paulo. São Paulo, 2013.

TILLEY, Christopher. "Archaeology as socio-political action in the present" In: Reader in Archaeology post-processual e cognitive approaches. David S. Whitley. New York e London: Routledge, 1998, p. 305-330. 
UCKO, Peter (ed.).Theory in Archaeology a world perspective. New York e London: TAG Routledge, 1995. 